\title{
Monitoring Tegangan Baterai Lithium Polymer pada Robot Sepak Bola Beroda secara Nirkabel
}

\author{
Rio Dwi Listianto ${ }^{1}$, Sunardi ${ }^{2}$, Riky Dwi Puriyanto ${ }^{3}$ \\ ${ }^{1}$ Mahasiswa Program Studi Teknik Elektro, Universitas Ahmad Dahlan, Indonesia \\ ${ }^{2,3}$ Dosen Program Studi Teknik Elektro, Universitas Ahmad Dahlan, Indonesia \\ Kampus 4 Jl. Ringroad Selatan, Tamanan, Banguntapan, Bantul, D. I. Yogyakarta 55191, Indonesia
}

\begin{tabular}{l} 
INFORMASI ARTIK \\
\hline Riwayat Artikel: \\
Dikirimkan 12 Juni 2019, \\
Direvisi 25 Juli 2019, \\
Diterima 10 Agustus 2019 \\
\hline Kata Kunci: \\
Monitoring Tegangan, \\
Lithium polymer, \\
Sensor tegangan, \\
NodeMCU, \\
Nirkabel.
\end{tabular}

INFORMASI ARTIKEL

Dikirimkan 12 Juni 2019,

Direvisi 25 Juli 2019,

Diterima 10 Agustus 2019.

\author{
Kata Kunci: \\ Monitoring Tegangan, \\ Lithium polymer, \\ NodeMCU, \\ Nirkabel.
}

\begin{abstract}
ABSTRAK
Baterai Lithium Polymer (Li-Po) dipilih sebagai sumber daya robot dikarenakan baterai Li-Po karena memiliki bobot yang ringan dan kapasitas penyimpanan listrik yang besar. Namun untuk mengetahui daya baterai yang digunakan, para pemilik robot harus menghentikan robot kemudian dilakukan pengukuran baterai menggunakan alat ukur. Penelitian ini bertujuan memantau nilai tegangan pada baterai Li-Po yang melalui motor penggerak pada robot sepakbola beroda tanpa menggunakan alat ukur dan hasilnya dapat ditampilkan pada komputer maupun PC secara nirkabel. Percobaan dilakukan menggunakan peralatan sensor tegangan dan modul wifi nodeMCU. Hasil dari penelitian ini sensor tegangan dapat membaca data dan didapat nilai standar deviasi 0,39 dan error rata-rata 0,43 yang menunjukkan bahwa sensor memiliki tingkat akurasi yang tinggi. Sementara untuk proses pemantauan sensor berjalan dengan lancar tanpa ada kendala.
\end{abstract}

This work is licensed under a Creative Commons Attribution-Share Alike 4.0

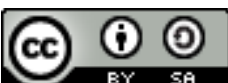

\author{
Penulis Korespondensi: \\ Rio Dwi Listianto, \\ Program Studi Teknik Elektro, Universitas Ahmad Dahlan, \\ Kampus 4 UAD, Jln. Ring Road Selatan, Tamanan, Banguntapan, Bantul, \\ Yogyakarta, Indonesia. \\ Surel: Riodwil58@gmail.com
}

\section{PENDAHULUAN}

Untuk meningkatkan kemampuan mahasiswa dalam bidang keilmuan dan kreativitas di bidang robotika perlu diadakannya Kontes Robot Sepakbola Indonesia Beroda. Dari kontes tersebut, diharapkan kemampuan mahasiswa dalam bidang mekanika, keterampilan, elektronika, pemrograman, kecerdasan buatan, pemrosesan gambar, komunikasi digital, strategi, kemampuan untuk meneliti, menulis artikel, kedisiplinan, toleransi, sportivitas, kerja sama, saling menghargai, kontrol emosi dan kemampuan softskill dapat berkembang. Kontes Robot Sepakbola Indonesia Beroda diselenggarakan menyesuaikan kondisi di Indonesia, misalnya untuk ukuran lapangan dan lain sebagainya. Hal tersebut sudah tercantum pada peraturan di RoboCup Middle Size League (MSL) [1].

Baterai merupakan suatu alat yang digunakan untuk mengubah energi kimia menjadi energi listrik, perubahan ini memanfaatkan prinsip transfer elektron dari satu material ke material lainnya melalui sirkuit elektrik [2]. Baterai yang digunakan untuk suatu perangkat bergerak (portable) saat ini terdiri dari 4 (empat) jenis baterai rechargeable yang telah digunakan secara tetap: Nikel Cadmium (NiCd), Nikel Metal Hybrid (NiMH), Lithium Ion (Li-Ion), dan Lithium Polymer (Li-Po) [2]. Baterai Li-Po (Lithium Polymer) tidak menggunakan cairan elektrolit melainkan menggunakan elektrolit polimer kering, yang berbentuk seperti lapisan plastik film tipis [3]. Sering dijumpai pada label di baterai lithium polymer yang sering kali disimbolkan dengan huruf "S". Dalam hal ini S berarti "sel" yang dimiliki paket baterai (battery pack), biasanya di bagian depan simbol terdapat bilangan yang menandakan jumlah sel, dan biasanya berkisar antara 2-6S. Setiap sel dalam baterai Li-Po memiliki tegangan nominal 3,6 V. Energi yang tersimpan dalam baterai, ditunjukkan dengan kapasitas yang tertera pada baterai dengan satuan miliampere hours (mAh) [3]. 
Baterai Li-Po memiliki kekurangan yaitu penurunan pada charging (pengisian daya) dan discharging rate (tahap pengisian daya). Hal ini disebabkan karena aliran pertukaran ion yang melalui elektrolit polimer kering tersebut lemah [4]. Hal ini akan mempengaruhi tingkat tegangan atau voltase yang dihasilkan oleh baterai LiPo [5]. Oleh karena itu perlu dilakukan pemantauan baterai, agar dapat diketahui tingkat tegangan yang ada pada baterai saat dipakai.

Pada saat ini pengukuran baterai LiPo masih menggunakan alat ukur manual untuk mengetahui tingkat baterai, hal ini akan mengganggu jalannya robot. Sehubungan dengan hal tersebut penelitian ini bertujuan untuk membuat alat yang dapat digunakan untuk memantau nilai tegangan yang dihasilkan oleh baterai LiPo tanpa menggunakan alat ukur manual, namun menggunakan sensor. Selain itu, agar tidak mengganggu jalannya robot, proses pembacaan dan pengiriman data dilakukan secara wifi atau secara nirkabel. Sensor yang digunakan pada penelitian ini menggunakan sensor tegangan. Sementara untuk modul wifi menggunakan nodeMCU.

\section{METODE PENELITIAN}

Objek penelitian ini adalah baterai lithium polymer 12V $2400 \mathrm{mAh}$ yang terdapat pada robot sepak bola beroda. Variabel yang diukur adalah nilai tegangan yang bersumber dari baterai lithium polymer. Baterai tersebut berfungsi sebagai sumber tegangan motor penggerak. pada penelitian ini dilakukan perubahan PWM agar dapat diketahui perbedaan tegangan yang terbaca oleh sensor tegangan. Hal ini dilakukan karena pada saat perubahan PMW, nilai tegangan yang masuk ke motor akan berubah.

\subsection{DESAIN SISTEM}

Desain hardware dari sistem monitoring dimana nodeMCU yang bertugas sebagai pengendali sensor dan juga sebagai pengolahan data yang terbaca oleh sensor. Desain sistem ini diprsentasikan dalam bentuk diagram blok yang akan membantu dalam membuat perancangan alat. Diagram blok perancangan hardware dapat dilihat pada Gambar 1.

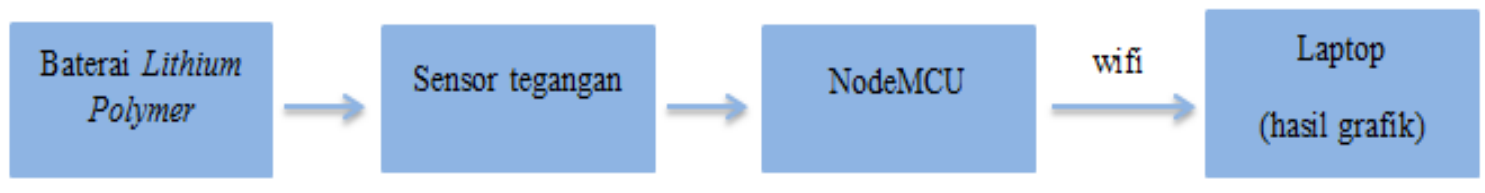

Gambar 1. Diagram blok perancangan hardware

Baterai lithium polymer digunakan untuk catu daya pada robot sepak bola beroda. Mikrokontroler sebagai pengolah dan pengirim data menggunakan nodeMCU. Sensor tegangan mulai membaca nilai tegangan pada baterai lithium polymer. NodeMCU mulai membaca data yang didapat oleh sensor tegangan. Kemudian nodeMCU mengirimkan data (nilai tegangan) ke web thingspeak menggunakan jaringan internet. Web thingspeak menampilkan hasil nilai tegangan dalam bentuk grafik.

Spesifikasi baterai lithium polymer memiliki kapasitas $150 \mathrm{Wh}$, dan memiliki tegangan awal 3,7 V, memiliki discharge yang tinggi [6]. Penelitian ini menggunakan sensor tegangan untuk membaca nilai tegangan DC yang keluar dari baterai lithium polymer. Spesifikasi sensor tegangan memiliki rentang tegangan yang di baca antara $0-25 \mathrm{~V}$, memiliki 3 pin masukan dan 2 buah pin keluaran, memiliki tegangan masukan 3,3 $\mathrm{V}$ hingga $5 \mathrm{~V}$ [7]. Untuk mikrokontroler menggunakan nodeMCU, spesifikasi nodeMCU memiliki ukuran panjang komponen $4,83 \mathrm{~cm}$, memiliki lebar komponen $2,54 \mathrm{~cm}$, dan berat 7 gram, pada nodeMCU ini sudah dilengkapi dengan fitur wifi dan Firmware yang bersifat opensource, Board nodeMCU ini berbasis ESP8266 serial WiFi SoC (Single on Chip) dengan onboard USB to TTL [8]. Pada komponen nodeMCU terdapat chip esp 8266 yang berfungsi sebagai chip wifi. Spesifikasi esp8266 memilikii wifi jenis $802.11 \mathrm{~b} / \mathrm{g} / \mathrm{n}$ tipe HT20, resolusi ADC 10 bit, memiliki tipe frekuensi $80 \mathrm{MHz}$ [9]. Monitoring penelitian ini menggunakan web thingspeak. Dengan kata lain penelitian ini memanfaatkan platform IoT. Platform IoT adalah suatu perangkat atau suatu program yang digunakan sebagai penghubung antara sensor yang digunakan dalam perangkat IoT dengan jaringan data. Thingspeak meruoakan platform open source dimana aplikasi Internet of things (IOT) dan Application Programming Interface (API) digunakan untuk menyimpan dan mengambil data dari suatu perangkat menggunakan protokol Hyper Text Transfer Protocol (HTTP) yang melalui Internet atau Local area network [10].

Perangkat nodeMCU dan sensor tegangan dirakit menjadi satu sistem, supaya dapat membaca nilai tegangan. Rangkaian keseluruhan sistem dapat dilihat pada Gambar 2. 


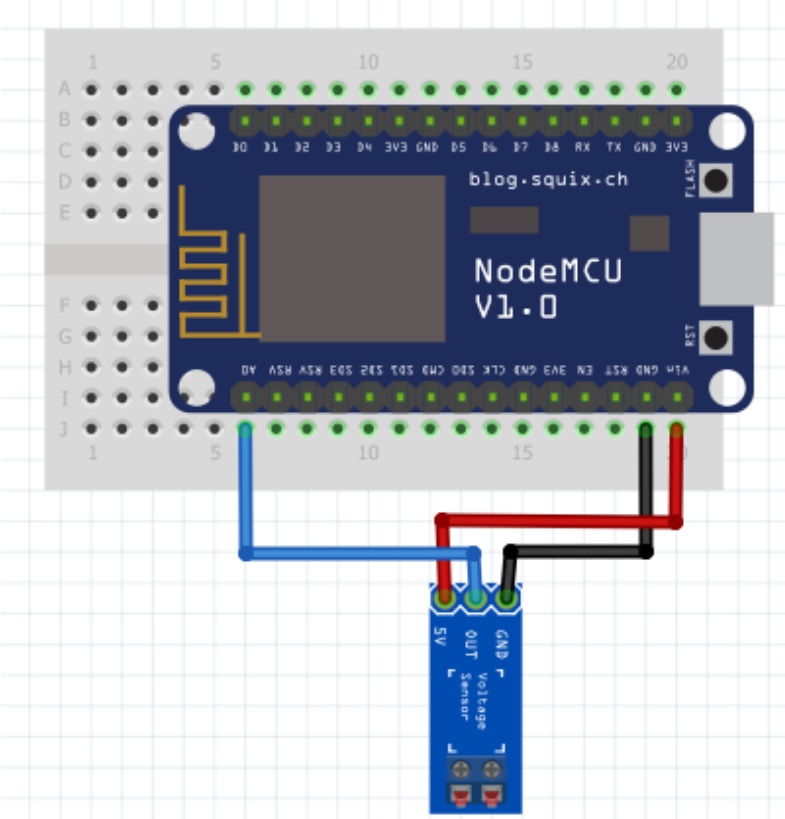

Gambar 2. Rangkaian keseluruhan sistem

Pada Gambar 2, nodeMCU adalah mikrokontroler sekaligus modul wifi, dan sensor tegangan. Sensor tegangan mendapat suplai daya dari nodeMCU sebesar $5 \mathrm{~V}$ dan dihubungkan dengan garis merah, sedangkan ground dihubungkan dengan garis hitam, adapun sensor tegangan agar dapat membaca data menggunakan analog read dalam nodeMCU ditunjukkan dengan A0, atau pada gambar dihubungkan menggunakan garis biru. Skematik sensor tegangan dapat dilihat pada Gambar 3.

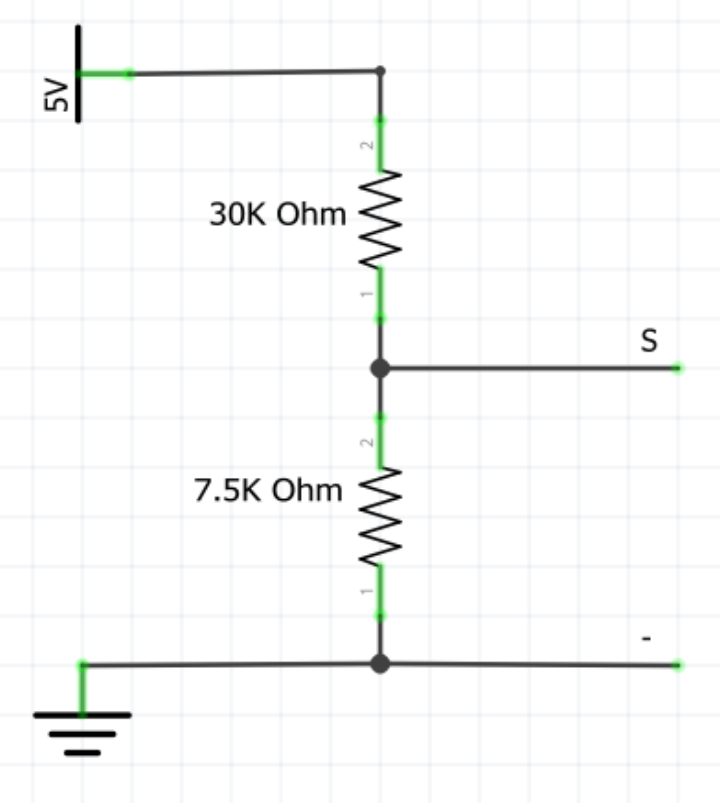

Gambar 3. Skematik sensor tegangan

\subsection{ALGORITMA}

Setelah desain perangkat keras selesai dikerjakan, langkah selanjutnya adalah desain perangkat lunak (program perintah). Desain perangkat lunak ini menggunakan software Arduino IDE yang selanjutnya di upload atau di downloadkan pada nodeMCU. Hal yang perlu dilakukan terlebih dahulu sebelum membuat program adalah membuat diagram alir (flowchart) yang bertujuan sebagai panduan untuk penulisan program. Flowchart algoritma sistem monitoring tegangan baterai dapat dilihat pada Gambar 4. 


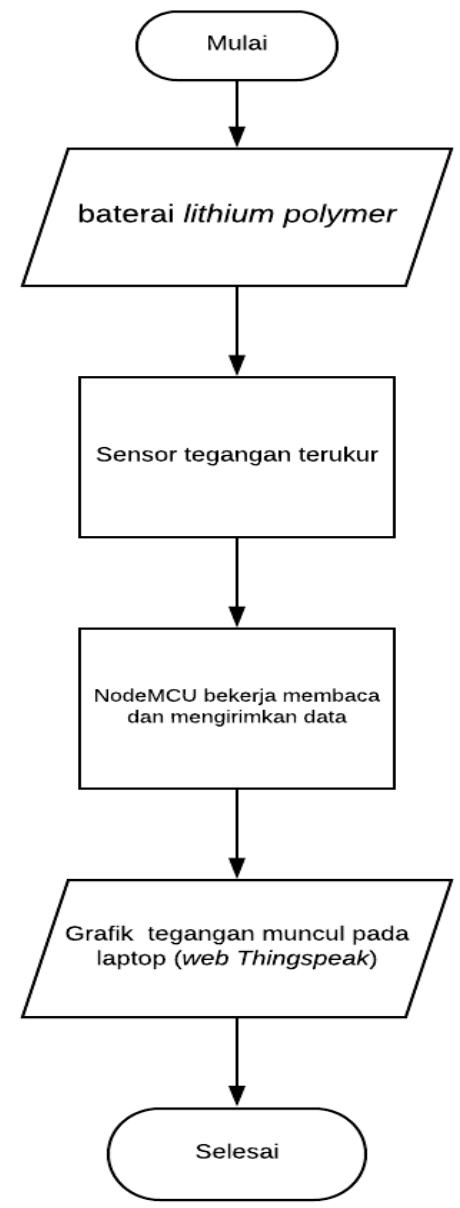

Gambar 4. Flowchart proses pembacaan dan pengiriman data

Berdasarkan Gambar 4 dapat diketahui bahwa pada saat baterai lithium polymer mulai bekerja. Sensor tegangan membaca nilai tegangan yang dihasilkan oleh baterai Li-Po. Hasil yang terbaca oleh sensor selanjutnya diolah oleh nodeMCU dan dikirimkan ke web thingspeak yang dapat ditampilkan pada laptop maupun PC. Hasil akhir adalah grafik yang menunjukkan nilai tegangan yang terukur oleh sensor. Agar proses dapat berjalan maka diperlukan program supaya dapat menjalankan sensor tegangan, nodeMCU. Program sensor tegangan yang digunakan dapat dilihat pada Listing 1 .

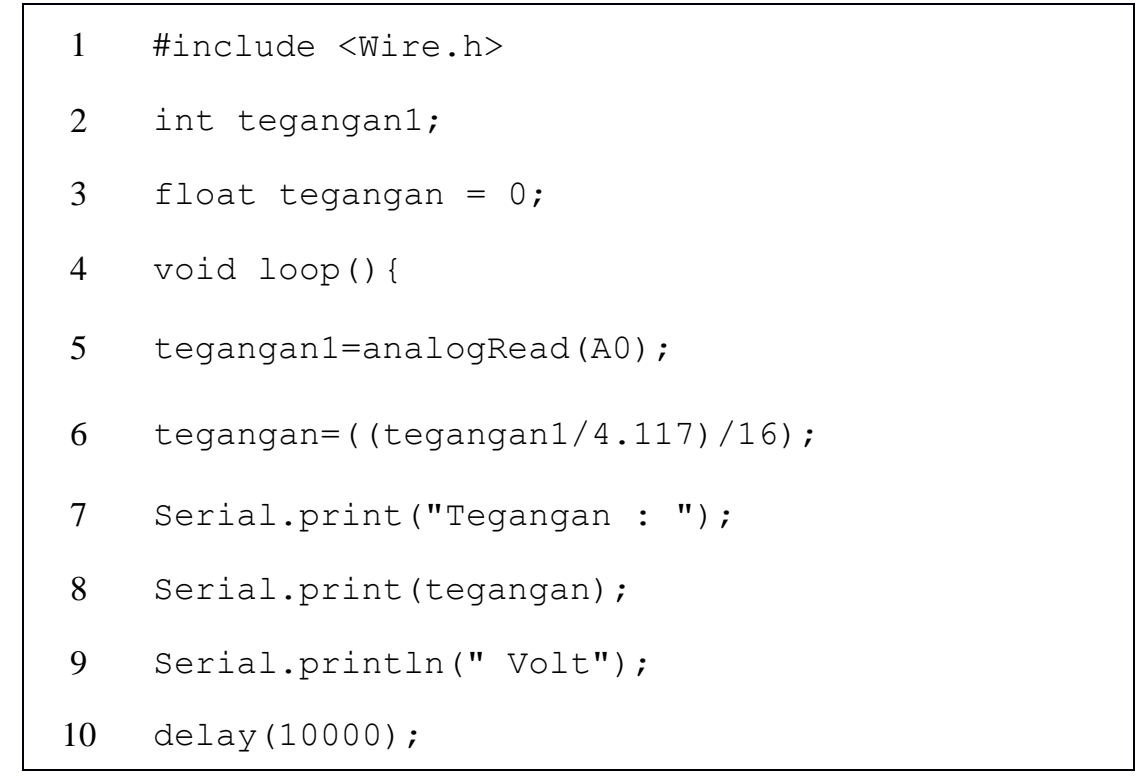

Listing 1. Program sensor tegangan 
Berikut penjelasan listing program sensor tegangan

1. Baris ke 1 \#include <Wire.h> digunakan untuk mendeklarasikan library yang digunakan sensor tegangan.

2. Baris ke 2 Int tegangan 1 merupakan listing yang berfungsi untuk menyimpan angka dalam 2 byte (16 bit).

3. Baris ke 3 void loop ( ) \{ berfungsi untuk mengulangi program yang dijalankan.

4. Baris ke 4 float tegangan $=00$; fungsinya adalah untuk menuliskan variabel dua angka di belakang koma.

5. Baris ke 5 Tegangan1=analogRead(A0); nilai analog yang digunakan untuk komunikasi (membaca data) antara sensor tegangan dan nodeMCU.

6. Baris ke 6 Tegangan=((tegangan1/4.117)/16); rumus yang digunakan untuk mengubah data mentah (nilai analog) menjadi nilai tegangan. Nilai analog yang terbaca oleh sensor kemudian dibagi dengan 4,117. Nilai 4,117 tersebut didapat dari hasil kalibrasi yang dilakukan menggunakan beberapa buah baterai. Sedangkan pembagian 16 (/16) merupakan jumlah baterai yang digunakan untuk mencari nilai kalibrasi.

7. Baris ke 7 Serial.print ("Tegangan : “); berfungsi untuk menuliskan kata Tegangan yang akan muncul di serial monitor.

8. Baris ke 8 Serial.print(tegangan); berfungsi untuk menampilkan hasil yang dibaca oleh sensor tegangan.

9. Baris ke 9 Serial.println(" Volt"); sama halnya dengan baris ke 7 listing ini juga berfungsi untuk menampilkan kata Volt pada serial monitor.

10. Baris ke 10 delay(10000); \} berfungsi untuk melakukan jeda waktu selama 20 detik.

\section{HASIL DAN PEMBAHASAN}

Pengujian dilakukan untuk mengecek rangkaian dari beberapa komponennya yang sudah bekerja secara optimal dan baik sehingga tidak terjadi masalah. Pengujian ini juga dimaksudkan untuk menyusun dan mengecek listing program pada software Arduino, agar program dapat diupload ke dalam nodeMCU dengan benar.

Pengujian ini dilakukan dengan mengubah PWM motor dari 50, 100, 150, 200. Nilai sensor yang didapat kemudian dibandingkan dengan nilai yang terbaca oleh alat ukur yaitu multimeter. Hasil perbandingan nilai tegangan dengan multimeter dapat dilihat pada Tabel 1.

Tabel 1. Hasil pengujian sensor tegangan

\begin{tabular}{ccccccc}
\hline PWM & $\begin{array}{c}\text { Waktu } \\
\text { pengujian }\end{array}$ & $\begin{array}{c}\text { Sensor } \\
(\mathbf{V})\end{array}$ & $\begin{array}{c}\text { Multimeter } \\
(\mathbf{V})\end{array}$ & Error & Deviasi & $\begin{array}{c}\text { Deviasi } \\
\text { kuadrat }\end{array}$ \\
\hline \multirow{6}{*}{$50: 50: 57$} & 10,54 & 11,15 & 0,61 & 0,17 & 0,03 \\
& $20: 51: 14$ & 10,51 & 11,15 & 0,64 & 0,20 & 0,04 \\
& $20: 51: 31$ & 10,51 & 11,15 & 0,64 & 0,20 & 0,04 \\
& $20: 51: 48$ & 10,58 & 11,15 & 0,57 & 0,13 & 0,01 \\
& $20: 52: 05$ & 10,3 & 11,15 & 0,85 & 0,4 & 0,17 \\
& $20: 52: 24$ & 10,15 & 11,1 & 0,95 & 0,51 & 0,26 \\
& $20: 52: 41$ & 10,14 & 11,11 & 0,97 & 0,53 & 0,28 \\
& $20: 52: 58$ & 10,15 & 11,23 & 1,08 & 0,64 & 0,41 \\
& $20: 53: 19$ & 10,47 & 11,25 & 0,78 & 0,34 & 0,11 \\
& $20: 53: 36$ & 10,51 & 11,1 & 0,59 & 0,15 & 0,02 \\
\hline \multirow{3}{*}{100} & $20: 26: 17$ & 9,27 & 10,23 & 0,96 & 0,96 & 0,92 \\
& $20: 26: 34$ & 10,57 & 10,23 & $-0,34$ & $-0,77$ & 0,60 \\
& $20: 26: 52$ & 9,84 & 10,25 & 0,41 & $-0,02$ & 0,00 \\
& $20: 27: 10$ & 9,61 & 10,24 & 0,63 & 0,19 & 0,03 \\
\hline
\end{tabular}




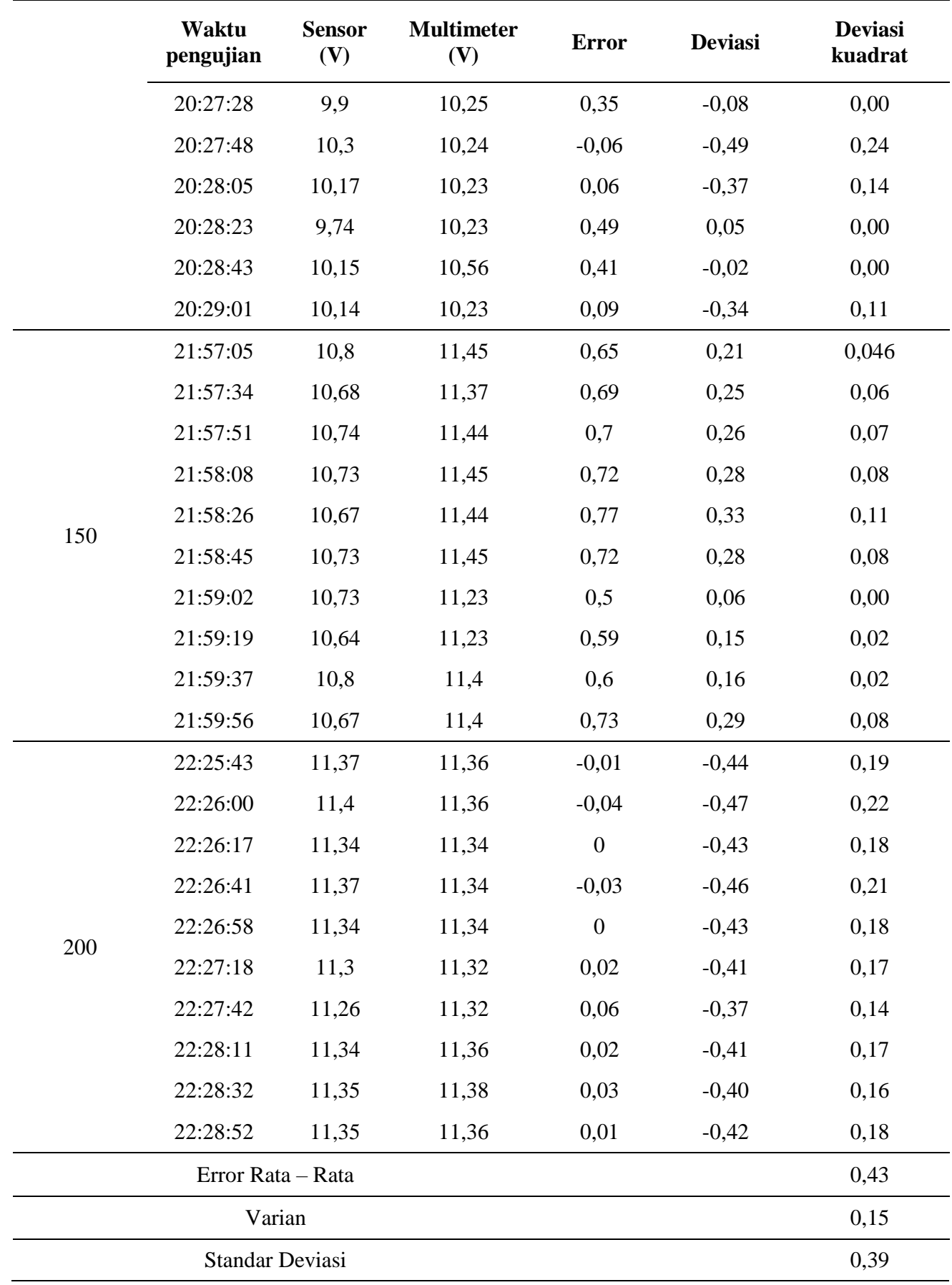

Berdasarkan hasil Tabel 1, hasil pengujian sensor tegangan memiliki error rata-rata 0,43. Berdasarkan hal tersebut dapat disimpulkan bahwa semakin kecil error rata-rata yang didapat dari suatu percobaan, semakin bagus sampling data yang kita ambil. Lalu, dapat dikatakan juga nilai tegangan yang dibaca sensor hampir sama dengan nilai yang dibaca alat ukur atau dalam penelitian ini menggunakan multimeter untuk membandingkan hasil yang dibaca oleh sensor.

Dari hasil Tabel 1 juga dapat diketahui nilai standar deviasi yang didapat adalah 0,39. Semakin rendah standar deviasi yang didapat, semakin mendekati rata-rata, sedangkan jika nilai standar deviasi semakin tinggi, semakin lebar pula rentang variasi datanya. Selain itu, dapat diartikan juga bahwa standar deviasi merupakan besar perbedaan dari nilai sampel terhadap rata-rata yang diperoleh.

Proses pemantauan ini dilakukan secara nirkabel agar tidak mengganggu jalannya robot. Hasil yang didapat oleh sensor tegangan dapat dilihat atau dipantau melalui web thingspeak. Hasil yang ditampilkan oleh web thingspeak berupa grafik. Pada grafik tersebut juga dapat disimpan dalam bentuk microsoft excel. Tampilan web thingspeak pada saat pemantauan dapat dilihat pada Gambar 5. 


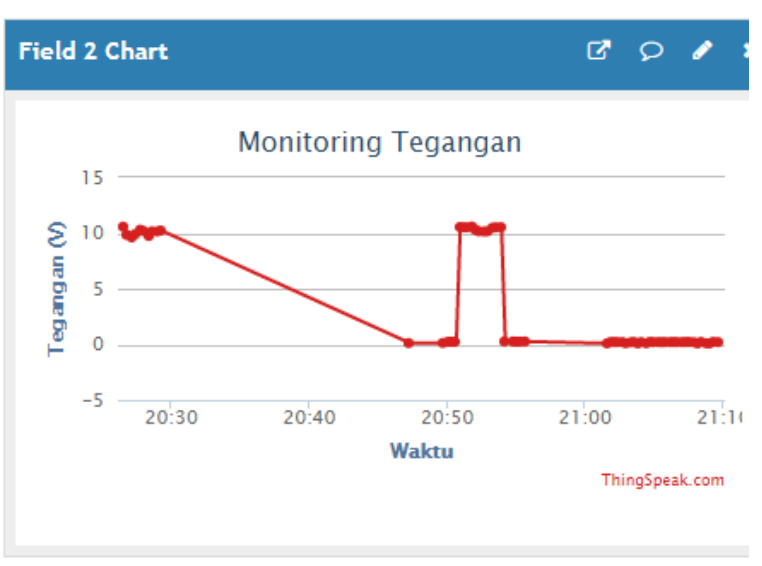

(a) PWM 50

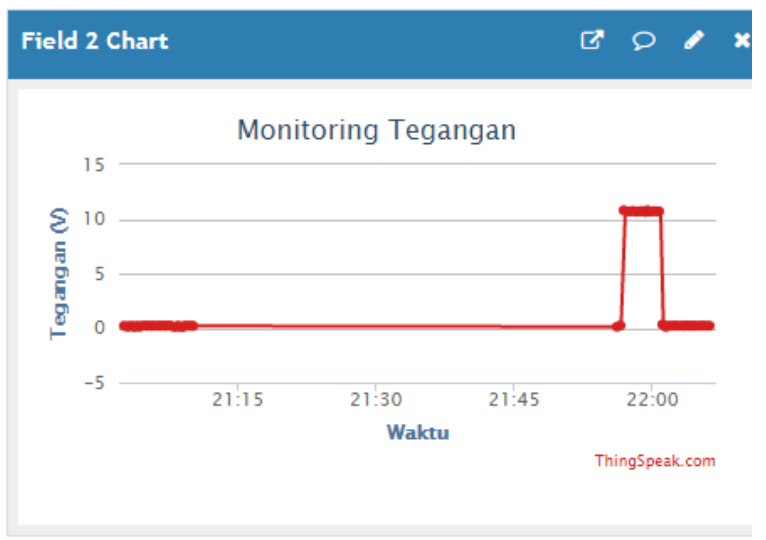

(c) PWM 150

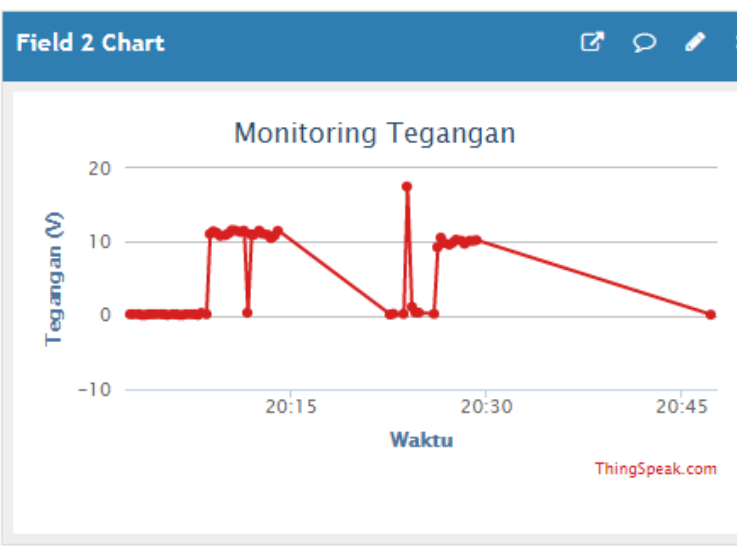

(b) PWM 100

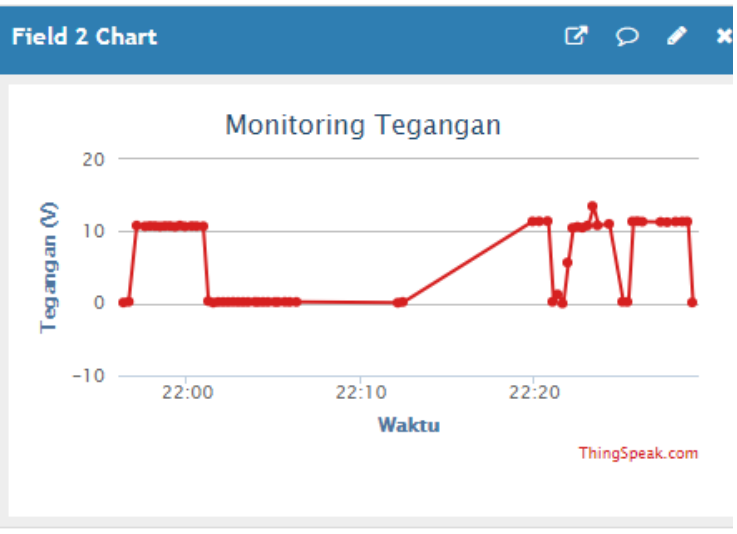

(d) PWM 200

Gambar 5. Hasil grafik monitoring tegangan

Keempat hasil grafik tersebut merupakan hasil grafik pengujian dengan nilai PWM yang diubah-ubah mulai dari 50, 100, 150, 200. Berdasarkan keempat grafik tersebut dapat dilihat pada sumbu Y yang tegak lurus ke atas menunjukkan nilai tegangan, sedangkan sumbu $X$ yang tegak lurus ke kanan menunjukkan waktu ketika nilai sensor terupload ke web thingspek. Pengujian fungsional merupakan pengujian untuk mengetahui alat secara keseluruhan, mulai dari sensor dan pengiriman data. Pengujian fungsional dilakukan dengan menjalankan fungsi alat secara keseluruhan. Hasil pengujian fungsi sensor tegangan dapat bekerja dan dapat membaca data tegangan, dengan rentang selisih $0,50 \mathrm{~V}$ jika dibandingkan dengan alat ukur multimeter. NodeMCU sebagai micro dan sekaligus modul wifi dapat terhubung dengan wifi yang telah dideklarasikan pada program. NodeMCU juga dapat mengirimkan data secara nirkabel dengan lancar. Web thingspeak dapat berfungsi dengan baik, web tersebut akan berjalan apabila ada koneksi. Lalu dapat dilakukan pemantauan secara real time.

\section{KESIMPULAN}

Berdasarkan hasil penelitian dan pembahasan dapat diambil kesimpulan bahwa proses pembacaan data tegangan menggunakan sensor tegangan dapat berjalan dengan baik. Nilai standar deviasi yang didapat dari sensor tegangan adalah 0,39 . Berdasarkan hasil tersebut menunjukkan bahwa alat yang dibuat mempunyai tingkat akurasi yang cukup bagus. Proses pengiriman data yang dilakukan menggunakan nodeMCU tidak mengalami kendala yang berarti. Hasil tegangan yang terbaca dapat ditampilkan melalui web thingspeak dengan delay 10 detik. Hal yang mempengaruhi keterlambatan pengiriman data dan ketidaksesuaian dengan program yang telah dibuat adalah koneksi yang kurang stabil.

\section{UCAPAN TERIMA KASIH}

Terima kasih tak lupa penulis ucapkan kepada editor dan reviewer atas semua saran dan masukkannya hingga terselesaikan jurnal ini. Tak lupa pula penulis mengucapkan terima kasih kepada semua pihak yang terkait dalam penyelesaian jurnal ini. Semoga kebaikan yang telah mereka berikan kepada penulis sebagai amalan ibadah dengan balasan pahala dari Allah Subhanahu wata'ala. Penulis mengharapkan agar tugas akhir 
ini dapat dimanfaatkan dengan sebaik-baiknya guna menambah ilmu pengetahuan bagi diri sendiri khususnya bagi para pembaca pada umumnya.

\section{REFERENSI}

[1] Ristekdikti, "Buku Panduan Kontes Robot Sepakbola Indonesia Beroda (KRSBI Beroda)," Direktorat Kemahasiswaan Direktorat Jenderal Pembelajaran Dan Kemahasiswaan Kementerian Riset, Teknologi Dan Pendidikan Tinggi Republik Indonesia, 2018.

[2] Setiawan, Muhammad Johan, "Baterai," Universitas Malikussaleh Lhokseumawe, 2014.

[3] Christian, Fendy, Mengenal Baterai Lithium Polymer (LiPo), Jakarta: Universitas Gunadarma. 2012.

[4] Ardyanto, B, Pengukuran tegangan, arus dan daya listrik menggunakan perangkat telepon pintar. 2019.

[5] Johanes Bismaputra, "Rancang Bangun Sistem Monitoring Tegangan Baterai pada Robot Pembersih Kaca Berbasis Wireless," Diploma thesis, Institut Teknologi Sepuluh Nopember, 2017.

[6] Afif, M. T., Ayu, I., \& Pratiwi, P., "Analisis Perbandingan Baterai Lithium-Ion, Lithium Polymer, Lead Acid Dan Nickel-Metal Hydride Pada Penggunaan Mobil Listrik,” Review. Jurnal Rekayasa Mesin, vol. 6, no, 2, pp. 95-99, 2015.

[7] Fitriandi, Afrizal, Rancang Bangun Alat Monitoring Arus dan Tegangan Berbasis Mikrokontroler dengan SMS Gateway. Jurnal Rekayasa dan Teknologi Elektro. Volume 10, No. 2, 2016.

[8] Banjari, Muhammad Arsyad Al.. "Desain Dan Implementasi Smart Home Berbasis WiFi”. Banjarmasin: Jurnal AI Ulum Sains dan Teknologi, 2017.

[9] B. Anilkumar, N. Lakshmidevi, and P. Choudary, "Home Automation through Smart Phone using ESP8266 Wi-Fi Module by IOT," vol. 3, no. 4, pp. 17-21, 2017.

[10] Saputra, Fajar Ananda, and Irawan Dwi Wahyono, "“WATERSOR” (Waterlogging Sensor) Monitoring Genangan Air di Kota Malang Berbasis ThingSpeak Framework," Prosiding SAKTI (Seminar Ilmu Komputer dan Teknologi Informasi), vol. 3, no. 2, 2019.

\section{BIOGRAFI PENULIS}

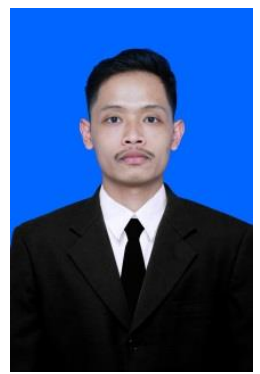

\section{Rio Dwi Listianto}

Lahir di Magelang tanggal 20 April 1994. Penulis pertama adalah mahasiswa Program Studi Teknik Elektro, Fakultas Teknologi Industri, Universitas Ahmad Dahlan Yogyakarta dan telah menyelesaikan pendidikan S1 pada program studi tersebut.

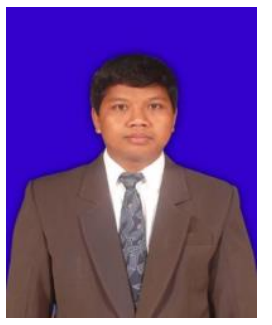

\section{Sunardi S.T., M.T., Ph.D.}

Lahir di Sragen tanggal 21 Mei 1974. Menyelesaikan pendidikan S1 Teknik Elektro di Universitas Gajah Mada Yogyakarta, S2 di Universitas Teknologi Bandung, dan S3 di Universitas Teknologi Malaysia. Bidang yang diminati beliau Wireless Communication. Saat ini beliau adalah dosen aktif di program studi Teknik Elektro Universitas Ahmad Dahlan dan Dekan FTI Universitas Ahmad Dahlan Yogyakarta.

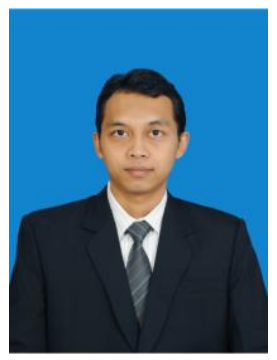

\section{Riky Dwi Puriyanto, S.T., M.Eng.}

Lahir di Sukoharjo tanggal 4 Mei 1988. Menyelesaikan pendidikan S1 Teknik Elektro di Universitas Gajah Mada Yogyakarta dan S2 Teknik Elektro di Universitas Gajah Mada Yogyakarta. Bidang yang diminati beliau Renewable Energy \& Signal Processing. Saat ini beliau menjabat sekretaris program studi teknik elektro di Universitas Ahmad Dahlan Yogyakarta. 